\title{
PENGARUH PENGEMBANGAN KARIR, KOMPENSASI DAN KOMITMEN ORGANISASIONAL TERHADAP RETENSI KARYAWAN PADA BINTANG KUTA HOTEL
}

\author{
Kadek Elsa Osiana Dewi ${ }^{1}$ \\ I Gede Riana ${ }^{2}$ \\ ${ }^{1,2}$ Fakultas Ekonomi dan Bisnis Universitas Udayana (Unud), Bali, Indonesia \\ E-mail:osianaelsa@yahoo.co.id
}

\begin{abstract}
ABSTRAK
Penelitian ini bertujuan untuk menjelaskan pengaruh kompensasi, pengembangan karir, dan komitmen organisasional terhadap retensi karyawan. Penelitian ini dilakukan di Bintang Kuta Hotel. Jumlah sampel yang diambil sebanyak 92 orang karyawan dengan metode sampling jenuh. Pada penelitian ini pengumpulan data dilakukan melalui penyebaran kuisioner dengan teknik analisis yang digunakan dalam penelitian ini adalah regresi linear berganda. Berdasarkan hasil analisis ditemukan bahwa kompensasi berpengaruh positif dan signifikan terhadap retensi karyawan. Pengembangan karir berpengaruh positif dan signifikan terhadap retensi karyawan. Komitmen organisasional berpengaruh positif dan signifikan terhadap retensi karyawan. Untuk meningkatkan retensi karyawan maka penting bagi perusahaan meninjau kembali kesesuaian gaji yang diterima dengan tingkat jabatan sehingga karyawan dapat merasakan kepuasan, kemudian untuk menumbuhkan komitmen diharapkan perusahaan mampu menjalin hubungan yang baik satu dengan yang lainnya dan perusahaan diharapkan mampu memberikan kontinuitas pelatihan kepada tiap karyawan dimana nantinya karyawan merasa diperhatikan dan dihargai kemampuannya sehingga memiliki keinginan kuat untuk tetap menjadi bagian didalam perusahaan.
\end{abstract}

Kata kunci: pengembangan karir, kompensasi, komitmen organisasional, retensi

\begin{abstract}
This study aims to explain the effects of compensation, career development, and organizational commitment to employee retention. The research was conducted at Bintang Kuta Hotel. The number of samples taken as many as 92 employees with saturated sampling method. In this study data collection is done through the distribution of questionnaires with analytical techniques used in this study is multiple linear regression. Based on the analysis results found that compensation has a positive and significant impact on employee retention. Career development has a positive and significant impact on employee retention. Organizational commitment has a positive and significant impact on employee retention. To increase employee retention it is important for the company to review the salary conformity received with the level of position so that employees can feel satisfaction, then to grow the expected commitment the company is able to establish good relationships with each other and the company is expected to provide continuity training to each employee where later employees feel cared for and appreciated ability so have a strong desire to remain part of the company.
\end{abstract}

Keywords: career development, compensation, organizational commitment, retention 


\section{PENDAHULUAN}

Berkembangnya suatu perusahaan tidak luput dari berbagai dukungan baik dukungan internal maupun eksternal perusahaan. Sumber Daya Manusia (SDM) merupakan salah satunya yang ada dalam suatu perusahaan.Manajemen sumber daya manusia merupakan peran strategis dalam perusahaan di mana manajemen sumber daya manusia ikut andil dalam merancang strategi perusahaan untuk mencapai tujuan dan mengubah rencana strategis tersebut ke dalam tindakan (Dessler, 2013).Permasalahan yang dihadapi manajemen dalam mencapai tujuan tersebut diantaranya adalah sumber daya manusia. Adanya sumber daya manusia yang potensial dan berkualitas, akan membantu perusahaan dalam mencapai sasaran. Saat ini untukmemperoleh sumber daya manusia yang berkualitas dan mempertahankan sumber daya manusia tersebut tidak mudah. Melihat hal tersebut, perusahaan senantiasa memberikan yang terbaik bagi karyawannya sehingga karyawan dapat berkontribusi secara optimal dalam peningkatan kinerja perusahaan.Perusahaan harus mempertahankan karyawannya selama mungkin terutama apabila karyawan tersebut memberikan dampak positif bagi perusahaan.

Penelitian ini dilakukan pada Bintang Kuta Hotel, Bali. Bintang Kuta Hotel merupakan sebuah hotel berstandar bintang empat yang terletak strategis yaitu pada daerah Kuta. Hotel ini tepatnya beralamat di Jalan Kartika Plaza Kuta, tentunya sangat dekat dengan objek wisata yang disukai wisatawan. Berdiri pada Tahun 2012 Bintang Kuta Hotel memiliki 168 kamar dengan fasilitas yang lengkap disertai pelayanan yang unggul dan bermutu.

Menurut Jennifer (2005:2) retensi karyawan adalah teknik yang digunakan

manajemen untuk mempertahankan karyawan agar tetap dalam 
perusahaan.Samuel dan Chipunza (2009) menyatakan tujuan utama dari retensi adalah mencegah keluarnya karyawan yang memiliki keahlian dari organisasi, karena dapat memiliki efek buruk pada produktivitas perusahaan. Sumarni (2011) juga menyatakan bahwa tingginya retensi karyawan sangat dibutuhkan dalam hal meningkatkan kinerja karyawan, jika employee retention rendah maka akan meningkatkan employee turnover sehingga mempunyai dampak negatif terhadap kinerja dan efektivitas perusahaan. Oleh karena itu, perusahaan dituntut untuk memperhatikan segala sesuatu yang berhubungan dengan hak karyawan.

Tingkat perputaran karyawan pada Bintang Kuta Hotel menunjukkan angka di atas batas normal. Menurut Nurhidayati (2016) retensi karyawan dapat dilihat melalui data turnover perusahaan. Menurut Gillies (1994) dalam (Setiawan, 2013) turnover karyawan dikatakan normal berkisar antara 5-10 persen per tahun, dan tergolong tinggi apabila lebih dari 10 persen per tahun. Data perputaran karyawan Bintang Kuta Hotel tahun 2014 - 2017 yang disajikan dalam tabel 1 menunjukkan masih tingginya turnover. Hal ini ditunjukkan dengan persentasi turnover karyawan Bintang Kuta Hotel dari tahun 2014 - 2017 yang masih diatas 10 persen dan di kategorikan diatas batas normal. Sehingga dapat disimpulkan bahwa dengan tingginya turnover, retensi di dalam perusahaan masih rendah. Untuk itu perusahaan dituntut meningkatkan retensi karyawan agar kinerja dan produktivitas perusahaan tetap terjaga. 
Tabel 1.

Data Jumlah Perputaran Karyawan Pada Bintang Kuta Hotel Tahun $2014-2017$

\begin{tabular}{cccccc}
\hline Tahun & $\begin{array}{c}\text { Jumlah } \\
\text { Karyawan }\end{array}$ & $\begin{array}{c}\text { Karyawan } \\
\text { Masuk }\end{array}$ & $\begin{array}{c}\text { Karyawan } \\
\text { Masuk } \\
(\boldsymbol{\%})\end{array}$ & $\begin{array}{c}\text { Karyawan } \\
\text { Keluar }\end{array}$ & $\begin{array}{c}\text { Karyawan } \\
\text { Keluar }(\%)\end{array}$ \\
\hline 2014 & 108 & 5 & 4,62 & 11 & 10,18 \\
2015 & 102 & 7 & 6,86 & 12 & 11,76 \\
2016 & 97 & 5 & 5,15 & 10 & 10,30 \\
2017 & 92 & 2 & 2,17 & 10 & 10,86 \\
\hline
\end{tabular}

Sumber: HRD Bintang Kuta Hotel Bali, 2017

Menurut Nurhidayati (2016) retensi karyawan dapat dilihat melalui data turnover karyawan. Gillies (1994) dalam Setiawan (2013) turnover karyawan dikatakan normal apabila karyawan keluar berkisar antara 5-10 persen per tahun, dan tergolong tinggi apabila lebih dari 10 persen per tahun.Data perputaran karyawan Bintang Kuta Hotel tahun 2014 - 2017 yang disajikan dalam Tabel 1.1 menunjukkan masih tingginya karyawan yang mengundurkan diri.Hal ini ditunjukkan dengan persentasi karyawan keluar Bintang Kuta Hotel dari tahun 2014 - 2017 yang masih diatas 10 persen dan di kategorikan diatas batas normal. Sehingga dapat disimpulkan bahwa dengan tingginya turnover, retensi di dalam perusahaan masih rendah. Untuk itu perusahaan dituntut meningkatkan retensi karyawan agar kinerja dan produktivitas perusahaan tetap terjaga.

Menurut Sumarni (2011), retensi karyawan merupakan kemampuan perusahaan untuk mempertahankan karyawan potensial yang dimiliki perusahaan untuk tetap loyal terhadap perusahaan.Segala bentuk sikap, keadaan, dan kondisi kerjakaryawan harus terjaga dengan harapan produktivitas karyawan dapat bertahan dengan baik bahkan mengalami peningkatan. Oleh karena itu, perusahaan dituntut untuk memperhatikan segala sesuatu yang berhubungan dengan hak karyawan. Menurut Jennifer (2005:2) retensi karyawan adalah teknik 
yang digunakan manajemen untuk mempertahankan karyawan agar tetap dalam perusahaan.Sumarni (2011) juga menyatakan bahwa tingginya retensi karyawan sangat dibutuhkan dalam hal meningkatkan kinerja karyawan, jika employee retention rendah maka akan meningkatkan employee turnover sehingga mempunyai dampak negatif terhadap kinerja dan efektivitas perusahaan. Oleh karena itu, perusahaan dituntut untuk memperhatikan segala sesuatu yang berhubungan dengan hak karyawan.

Dalam meningkatkan retensi karyawan, perusahaan harus memperhatikanfaktor seperti penerapan kebijakan pengembangan terhadap karyawan, karena kebijakan pengembangan tersebut dirasa dapat memberikan motivasi kerja terhadap karyawan.Menurut Mathis dan Jackson (2006:128) retensi karyawan dipengaruhi oleh faktor pengembangan karir secara siginifikan.Pengembangan karir merupakan aspek penting yang tidak boleh dilupakan dalam mengelola sumber daya manusia (Sari dan Sinulingga, 2011). Pengembangan karir meliputi kesempatan untuk pelatihan, promosi jabatan dan pengembangan keterampilan guna meningkatkan kerja karyawan dalam suatu perusahaan (Meyer \& Smith, 2000). Kwenin (2013) menyatakan bahwa perusahaan yang memberikan pelatihan dan fasilitas pendidikan kepada karyawan maka karyawan tersebut lebih berkomitmen dan setia kepada organisasi. Begitu juga karyawan yang diberikan pendidikan serta pelatihan akan mampu dalam meningkatkan produktivitas pada perusahaan.Sutherland (2004) menyatakan bahwa organisasi yang memberikan pengembangan karir kepada karyawan, secara tidak langsung yang berhubungan dengan pekerjaan mereka maka karyawan 
cenderung mempertahankan pekerjaan mereka untuk dapat memperoleh pengetahuan yang lebih luas.Sitati et al. (2016) menyatakan bahwa pengembangan karir dapat mempengaruhi secara positif dan signifikan terhadap retensi karyawan pada industri hotel di Kenya.Woodruff (1999) berpendapat bahwa retensi di dalam perusahaan akan tetap terjaga dengan memanfaatkan sumber daya manusia untuk diberikan pelatihan dan pengembangan.

Selain faktor pengembangan karir,pemberian kompensasi juga dapat mempengaruhi karyawan bertahan pada suatu organisasi. Kompensasi yang baik akan meningkatkan retensi karyawan dalam perusahaan. Hasibuan (2011: 118), menyatakan bahwa kompensasi adalah suatu pendapatan berupa barang, uang dan lain sebagainya yang akan didapat oleh karyawan sebagai suatu imbalan. Mudayen (2010), kompensasi yaitu imbalan atau balas jasa yang diberikan secara teratur oleh perusahaan baik berupa uang (financial) maupun bukan uang (non financial). Lubis (2015) menyatakan kompensasi merupakan hal penting bagi karyawan, karenakompensasi merupakan bentuk nilai yang diterima oleh karyawan atas kinerjanya. Sumarto (2009) menyatakan bahwa semakin menarik faktor kompensasi maka akan semakin mengurangi niat karyawan untuk meninggalkan organisasi sehingga retensi tetap terjaga. Sebaliknya semakin rendah tingkat kompensasi yang diterima semakin mendorong karyawan untuk meninggalkan organisasi dan mencari alternatif pekerjaan di tempat sehingga retensi menjadi menurun. Penelitian yang dilakukan Sarmand et al. (2016)menyatakan bahwa adanya hubungan yang positif dan signifikan antara kompensasi dengan retensi karyawan pada oganisasi penjualan minyak dan gas 
sektor publik di Pakistan. Begitu pula dengan hasil penelitian yang dilakukan oleh Kumar et al. (2012) bahwa adanya hubungan positif antara kompensasi dengan retensi karyawan.

Selain harus memperhatikan pengembangan karir dan pemberian kompensasi pada karyawan, perusahaan perlu memperhatikan seberapa besar komitmen organisasional dari karyawan tersebut.Komitmen organisasional merupakan faktor pendukung retensi karyawan.Komitmen merupakan sikap yang merefleksikanloyalitaskaryawan pada perusahaan dan prosesnya berkelanjutan, dimana anggota perusahaan mengekspresikan perhatiannya dan keberhasilan serta kemajuan secara berkelanjutan terhadap perusahaan (Dockel, 2006). Menurut Robbins (2015) komitmen organisasional merupakan keadaan di mana karyawan memihak suatu perusahaan serta mempertahankan keanggotaannya dalam perusahaan tersebut.Komitmen diartikan sebagai sikap karyawan untuk tetap berada dalam perusahaan dan terlibat dalam upaya-upaya mencapai misi, nilainilai dan tujuan perusahaan. Rose, S. and Raja, K.G. (2016) menemukan bahwa komitmen organisasional berpengaruh secara signifikan terhadap retensi karyawan. Sama halnya dengan Coetzee and Botha (2012) menemukan bahwa komitmen organisasional berpengaruh secara positif dan signifikan terhadap retensi karyawan. Dengan memberi perhatian penuh dan membuat karyawan percaya terhadap perusahaan akan diperoleh komitmen karyawan. Jika komitmen karyawan telah diperoleh maka akan didapatkan karyawan yang memiliki loyalitas tinggi, sehingga retensi perusahaan dapat terjagabahkan meningkat. 
Berdasarkan wawancara yang dilakukan pada Bintang Kuta Hotel Bali, faktor- faktor seperti pengembangan karir, kompensasi dan komitmen organisasional memainkan peran penting dalam mendorong keinginan karyawan untuk tetap berada di Bintang Kuta Hotel Bali. Hal ini dapat dilihat dari beberapa keluhan yang muncul dari karyawan, seperti mendapat pelatihan yang tidak merata, gaji yang tidak sesaui dengan jabatan, dan masih adanya keinginan untuk mencari pekerjaan di tempat lain dikarenakan ketidakpuasan.

Retensi karyawan merupakan proses di mana karyawan didorong untuk tetap dengan organisasi untuk periode maksimum waktu atau sampai selesainya proyek (Karthi, 2012). Menurut Ragupathi (2013), retensi karyawan mengacu pada teknik yang digunakan oleh manajemen untuk membantu karyawan tetap dengan organisasi untuk jangka waktu yang lama. Menurut Sumarni (2011), retensi karyawan merupakan kemampuan perusahaan untuk mempertahankan karyawan potensial yang dimiliki perusahaan untuk tetap loyal terhadap perusahaan.

Tujuan utama penelitian ini adalah untuk menguji apakah ada pengaruh antara pengembangan karir, kompensasi dan komitmen organisasi terhadap retensi karyawan. 


\section{Gambar 1.Kerangka Konseptual}

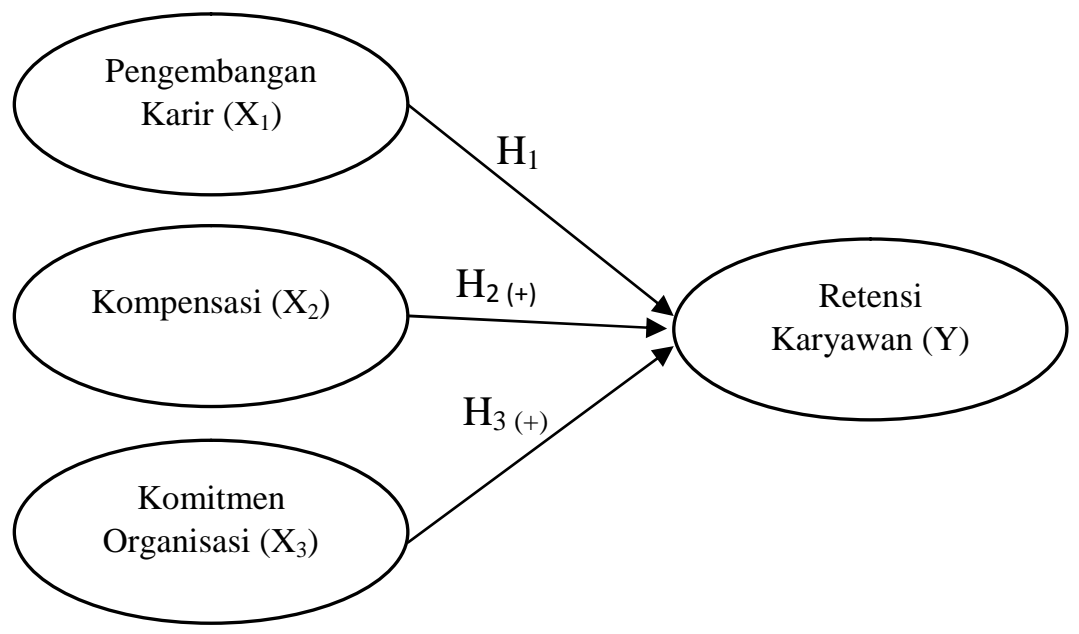

Sumber:

$\mathrm{H}_{1}$ : Pratiwi and Sriathi (2017), Kwenin (2013), Sitati et al., (2016), Sutherland (2004), Cardy and Lengnick-Hall (2011), Kroon and Freese (2013), Prince (2005), Ongori Agolla (2009), Cho et al., (2009).

$\mathrm{H}_{2}$ : Putra and Agoes (2016), Kumar et al., (2012), Hafanti (2015), Anis (2011), Sarmand et al., (2016), Milkovich and Newman (2004), Panggabean (2014), Michael et al., (2016), Sumarto (2009).

$\mathrm{H}_{3}$ : Fukuoka (2014), Atif Anis et al., (2011), Mowday et al., (1982), Naqvi, S. M. M. R. and Bashir, S. (2015), Rose, S. and Raja, K. G. (2016), Cootze and Botha (2012), Tung et al., (2014), Mehta et al., (2014).

Sutherland (2004) menyatakan bahwa organisasi yang memberikan pengembangan karir kepada karyawan, secara tidak langsung berhubungan dengan pekerjaan mereka maka karyawan cenderung mempertahankan pekerjaan mereka untuk dapat memperoleh pengetahuan yang lebih luas. Cardy and Lengnick-Hall (2011) begitu juga dengan Kroon and Freese (2013) menemukan bahwa peluang pengembangan karir dapat secara positif meningkatkan komitmen karyawan untuk tinggal di organisasi. Prince (2005) menyarankan bahwa organisasi harus mendukung karyawan untuk membuat komitmen jangka panjang 
kepada karyawan melalui peningkatan program pelatihan dan pengembangan karir. Hal serupa juga dikatakan oleh Ongori and Agolla (2009), bahwa kurangnya pengembangan karir dalam organisasi akan menyebabkan peningkatan niat karyawan untuk meninggalkan organisasi.Penelitian ini juga sejalan dengan Cho et al.(2009) yang menyatakan bahwa sebuah organisasi yang ingin memperkuat hubungan dan mempertahankan karyawan harus menjalankan pengembangan karyawan dengan cara organisasi perlu menjalankan program-program pelatihan dan pengembangan kepada karyawan.

$\mathrm{H}_{1}$ : Pengembangan Karir berpengaruh positif dan signifikan terhadap retensikaryawan.

Menurut penelitian yang dilakukan oleh Putra and Agoes (2016) menyatakan bahwa kompensasi memiliki pengaruh positif terhadap retensi karyawan pada Green Villas Hotel Tuban Bali. Begitu juga dengan hasil penelitian yang dilakukan oleh Kumar et al. (2012) menemukan bahwa adanya hubungan positif antara kompensasi dengan retensi karyawan. Berdasarkan penelitian yang dilakukan oleh Hafantiet al. (2015), yang berjudul pengaruh kompensasi, lingkungan kerja dan desain tugas terhadap kepuasan kerja dan dampaknya terhadap retensi karyawan membuktikan bahwa kompensasi berpengaruh positif terhadap retensi karyawan. Anis et al. (2011) melakukan penelitian yang berjudul Employee Retention Relationship to training and development: A compensation perspective dimana hasil yang di dapat bahwa kompensasi berpengaruh positif terhadap retensi karyawan. Sarmand et al. (2016) menyatakan bahwa adanya hubungan yang positif dan signifikan antara 
kompensasi dengan retensi karyawan pada oganisasi penjualan minyak dan gas sektor publik di Pakistan.

Milkovich and Newman (2004) menuliskan bahwa kompensasi sebagai faktor yang paling relevan dalam mempertahankan karyawan. Milkovich and Newman (2004) menuliskan bahwa kompensasi sebagai faktor yang paling relevan dalam mempertahankan karyawan. Hasil penelitian ini sesuai dengan penelitian yang dilakukan oleh Panggabean (2014) dimana variabel kompensasi memiliki pengaruh positif dan signifikan terhadap retensi karyawan. Ini menunjukan bahwa semakin besar kompensasi maka akan semakin tinggi tingkat retensi karyawan. Karyawan akan merasa dihargai oleh perusahaan jika karyawan mendapatkan kompensasi yang layak sehingga karyawan akan termotivasi dan akan bekerja lebih baik untuk perusahaan dan secara tidak langsung karyawan akan bertahan di dalam perusahaan.

Hipotesis ini juga didukung dari penelitian yang dilakukan Michael et al. (2016) dengan hasil dimana kompensasi berpengaruh positif dan signifikan terhadap retensi karyawan. Begitu juga dengan penelitian Sumarto (2009) menunjukan bahwa semakin menarik faktor kompensasi akan semakin mengurangi niat karyawan untuk meninggalkan organisasi sehingga retensi tetap terjaga. Sebaliknya semakin rendah tingkat kompensasi yang diterima semakin mendorong karyawan untuk meninggalkan organisasi dan mencari alternatif pekerjaan di tempat sehingga retensi menjadi menurun.

$\mathrm{H}_{2}$ : Kompensasi berpengaruh positif dan signifikan terhadap retensi karyawan. 
Dalam penelitian Fukuoka (2014) dimana hasil dari variabel komitmen organisasional mempunyai hubungan yang positif terhadap retensi karyawan. Kemudian penelitian dari Aniset al.(2011) menyimpulkan bahwa komitmen organisasi memiliki hubungan yang kuat dan positif dengan retensi karyawan pada industri farmasi di Pakistan. Mowday et al. (1982:219) mengatakan bahwa komitmen organisasional sebagai kepercayaan dan penerimaan yang kuat terhadap tujuan organisasi sehingga berpengaruh terhadap keinginan untuk mempertahankan diri sebagai anggota organisasi. Naqvi, S. and Bashir, S. (2015) menyatakan bahwa terdorongnya komitmen organisasional pada karyawan akan meningkatkan retensi karyawan. Rose, S. and Raja, K.G. (2016) menemukan bahwa komitmen organisasional berpengaruh secara signifikan terhadap retensi karyawan. Coetzee and Botha (2012) menemukan bahwa komitmen organisasional berpengaruh secara positif dan signifikan terhadap retensi karyawan. Tung et al. (2014) dalam penelitiannya menunjukkan bahwa seluruh komponen (afektif, berkelanjutan, dan normatif) dari komitmen organisasional berhubungan positif dan signifikan dengan retensi karyawan. Mehta et al. (2014) menyatakanagar organisasi dapat bertahan dalam persaingan yang semakin hari semakin meningkat, sangat penting untuk mempertahankan karyawan terbaik mereka yaitu dengan menjaga komitmen mereka terhadap organisasi.

$\mathrm{H}_{3}$ : Komitmen organisasional berpengaruh positif dan signifikan terhadap retensikaryawan. 


\section{METODE PENELITIAN}

Lokasi penelitian ini adalah pada Bintang Kuta Hotel di Jalan Kartika Plaza, Kecamatan Kuta, Kabupaten Badung, Bali. Lokasi ini dipilih karena ditemukan masalah mengenai retensi karyawan, dimana diduga tingkat retensi karyawan dipengaruhi oleh pengembangan karir, kompensasi dan komitmen organisasional. Selain itu lokasi pemilihan didasarkan atas tersedianya data yang memadai, mampu untuk diolah dan belum pernah ada penelitian di lokasi ini mengenai pengaruh pengembangan karir, kompensasi dan komitmen organisasional terhadap retensi karyawan.

Populasi penelitian ini adalah seluruh karyawan pada Bintang Kuta Hotel yaitu berjumlah 92 orang, maka peneliti mengambil sampel dari seluruh populasi tersebut sehingga menggunakan sampel jenuh.

Teknik analisis data dalam penelitian ini dengan menggunakan teknik analisis linear berganda. Model analisis linear berganda dengan menggunakan persamaan sebagai berikut :

$\mathrm{Y}=\alpha+\beta_{1} \mathrm{X}_{1}+\beta_{2} \mathrm{X}_{2}+\beta_{3} \mathrm{X}_{3}+\mathrm{e}$

Keterangan :

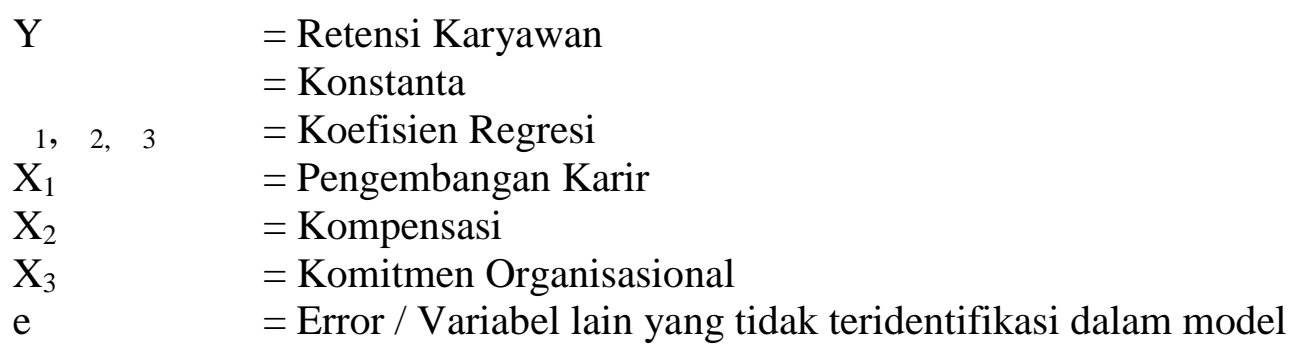

Pengaruh variabel dependen terhadap variabel independen diuji dengan tingkat kepercayaan $95 \%$ atau $\alpha=5 \%$. 


\section{HASIL PENELITIAN DAN PEMBAHASAN}

Berdasarkan data dari 92 responden Bintang Kuta Hotel karakterstik responden dilihat dari beberapa kriteria, yaitu jenis kelamin, usia, jabatan dan masa kerja. Karakteristik responden diuraikan pada tabel 2 yaitu sebagai berikut:

Tabel 2.

Karakteristik Responden

\begin{tabular}{|c|c|c|c|c|}
\hline No. & Variabel & Klasifikasi & $\begin{array}{l}\text { Jumlah } \\
\text { (Orang) }\end{array}$ & $\begin{array}{c}\text { Persentase } \\
(\%)\end{array}$ \\
\hline \multirow[t]{4}{*}{1.} & \multirow[t]{2}{*}{ Jenis Kelamin } & Laki - laki & 63 & 68,5 \\
\hline & & Perempuan & 29 & 31,5 \\
\hline & \multicolumn{2}{|c|}{ Jumlah } & 92 & 100 \\
\hline & & $20-30$ & 36 & 39,1 \\
\hline \multirow[t]{9}{*}{2.} & \multirow[t]{9}{*}{ Usia } & $30-40$ & 25 & 27,1 \\
\hline & & $40-50$ & 22 & 24 \\
\hline & & Diatas 50 & 9 & 9,8 \\
\hline & & & 92 & 100 \\
\hline & & Executive Office & 4 & 4,3 \\
\hline & & Human Resources & 2 & 2,2 \\
\hline & & Sales \& Marketing & 2 & 2,2 \\
\hline & & Reservation & 2 & 2,2 \\
\hline & & Accounting & 9 & 9,8 \\
\hline \multirow[t]{8}{*}{3.} & \multirow[t]{6}{*}{ Jabatan } & Purchasing & 2 & 2,2 \\
\hline & & Front Office & 18 & 19,6 \\
\hline & & F\&B Service & 14 & 15,2 \\
\hline & & Kitchen & 9 & 9,8 \\
\hline & & Engineering & 10 & 10,8 \\
\hline & & Housekeeping & 20 & 21,7 \\
\hline & \multicolumn{2}{|c|}{ Jumlah } & 92 & 100 \\
\hline & & $>1$ & 2 & 2,8 \\
\hline \multirow[t]{3}{*}{4.} & \multirow[t]{2}{*}{ Masa Kerja } & $1-3$ & 14 & 15,2 \\
\hline & & $<3$ & 76 & 82,6 \\
\hline & \multicolumn{2}{|c|}{ Jumlah } & 92 & 100 \\
\hline
\end{tabular}

Sumber: Data diolah, 2018

Pertanyaan - pertanyaan dalam kuesioner dikatakan valid apabila koefisien korelasi $\geq 0,3$ Sugiyono (2016:143). Uji validitas bertujuan untuk memeriksa apakah kuisioner sebagai instrumen penelitian sudah tepat untuk mengukur indikator dalam penelitian. Kuesioner dapat dikatakan valid apabila pertanyaan 
dalam kuesioner mampu mengungkap sesuatu yang akan diukur oleh kuesioner tersebut.

Tabel 3.

Hasil Uji Validitas Instrumen

\begin{tabular}{|c|c|c|c|c|}
\hline No & Variabel & Indikator & $\begin{array}{c}\text { Koefisien } \\
\text { Korelasi }\end{array}$ & Keterangan \\
\hline \multirow{5}{*}{1.} & \multirow{5}{*}{$\begin{array}{c}\text { Pengembangan Karir } \\
\left(\mathrm{X}_{1}\right)\end{array}$} & $\mathrm{X}_{1.1}$ & 0,813 & Valid \\
\hline & & $\mathrm{X}_{1.2}$ & 0,795 & Valid \\
\hline & & $\mathrm{X}_{1.3}$ & 0,787 & Valid \\
\hline & & $\mathrm{X}_{1.4}$ & 0,829 & Valid \\
\hline & & $\mathrm{X} 1.5$ & 0,739 & Valid \\
\hline \multirow{6}{*}{2.} & \multirow{6}{*}{$\begin{array}{l}\text { Kompensasi } \\
\quad\left(\mathrm{X}_{2}\right)\end{array}$} & $\mathrm{X}_{2.1}$ & 0,859 & Valid \\
\hline & & $\mathrm{X}_{2.2}$ & 0,762 & Valid \\
\hline & & $\mathrm{X}_{2.3}$ & 0,852 & Valid \\
\hline & & $\mathrm{X}_{2.4}$ & 0,837 & Valid \\
\hline & & $\mathrm{X}_{2.5}$ & 0,851 & Valid \\
\hline & & $\mathrm{X}_{2.6}$ & 0,906 & Valid \\
\hline \multirow{6}{*}{3.} & \multirow{6}{*}{$\begin{array}{l}\text { Komitmen Organisasional } \\
\qquad\left(\mathrm{X}_{3}\right)\end{array}$} & $\mathrm{X}_{3.1}$ & 0,808 & Valid \\
\hline & & $\mathrm{X}_{3.2}$ & 0,703 & Valid \\
\hline & & $\mathrm{X}_{3.3}$ & 0,865 & Valid \\
\hline & & $X_{3.4}$ & 0,785 & Valid \\
\hline & & $\mathrm{X}_{3.5}$ & 0,931 & Valid \\
\hline & & $X_{3.6}$ & 0,837 & Valid \\
\hline \multirow{5}{*}{4.} & \multirow{5}{*}{$\begin{array}{l}\text { Retensi } \\
(\mathrm{Y})\end{array}$} & $\mathrm{Y}_{1.1}$ & 0,822 & Valid \\
\hline & & $\mathrm{Y}_{1.2}$ & 0,848 & Valid \\
\hline & & $Y_{1.3}$ & 0,880 & Valid \\
\hline & & $\mathrm{Y}_{1.4}$ & 0,883 & Valid \\
\hline & & $\mathrm{Y}_{1.5}$ & 0,868 & Valid \\
\hline
\end{tabular}

Sumber:Data diolah, 2018

Hasil uji validitas pada Tabel 3 menunjukan bahwa seluruh variabel memiliki nilai koefisien korelasi lebih besar dari $0,3(\mathrm{r}>0,3)$. Hal ini menyatakan bahwa seluruh butir pernyataan dalam instrumen penelitian tersebut valid.

Oleh karena itu, instrumen yang valid pada umumnya pasti reliabel, tetapi pengujian reliabilitas instrumen perlu dilakukan untuk mencari tahu sampai sejauh mana konsistensi alat ukur yang digunakan, sehingga bila alat ukur tersebut digunakan kembali untuk meneliti objek yang sama dengan teknik yang sama walaupun waktunya berbeda, maka hasil yang akan diperoleh akan sama 
Sugiyono (2016:142). Reliabilitas instrumen merupakan syarat untuk pengujian validitas intrumen. Suatu konstruk atau variabel dikatakan reliabel jika memberikan nilai Cronbach Alpha > 0,60.

Tabel 4.

Hasil Uji Reliabilitas Instrumen

\begin{tabular}{clcc}
\hline No. & \multicolumn{1}{c}{ Variabel } & Cronbadh'sAlpha & Keterangan \\
\hline 1. & Pengembangan Karir $\left(\mathrm{X}_{1}\right)$ & 0,840 & Reliabel \\
2. & Kompensasi $\left(\mathrm{X}_{2}\right)$ & 0,916 & Reliabel \\
3. & Komitmen Organisasional $\left(\mathrm{X}_{3}\right)$ & 0,901 & Reliabel \\
4. & Retensi $(\mathrm{Y})$ & 0,910 & Reliabel \\
\hline
\end{tabular}

Sumber:Data diolah, 2018

Hasil uji reliabilitas pada Tabel 4. menunjukan bahwa seluruh instrumen penelitian memiliki koefisien Cronbach's Alpha lebih besar dari 0,6. Hal ini menyatakan bahwa seluruh instrumen reliabel sehingga dapat digunakan untuk melakukan penelitian.

Uji normalitas bertujuan untuk menguji apakah dalam residual dari model regresi variable bebas dan variable terikat atau keduanya terdistribusikan secara normal atau tidak. Hasil uji normalitas dapat dilihat pada Tabel 5 sebagai berikut.

Tabel 5.

\section{Hasil Uji Normalitas}

\begin{tabular}{lc}
\hline & Unstandardized Residual \\
\hline $\mathrm{N}$ & 92 \\
Test Statistic & 0,521 \\
Kolmogorov-Smirnov $\mathrm{Z}$ & \\
Asymp.Sig.(2-tailed) & 0,949 \\
\hline
\end{tabular}

Sumber: Data diolah, 2018

Berdasarkan Tabel 5 dapat dilihat bahwa nilai Test Statistic KolmogorovSmirnov sebesar 0,521 dan nilai Asymp.Sig sebesar 0,949 lebih besar dari 0,05 ini berarti residual dari persamaan regresi dalam penelitian ini terdistribusi secara normal. Nilai Kolmogorov-Smirnov merupakan koefisien yang digunakan untuk 
mengukur kenormalan distribusi data. Semakin besar nilai Kolmogorov-Smirnov maka semakin kecil nilai probabilitasnya (Asym.Sig) dan semakin besar nilai Kolmogorov-Smirnov maka semakin tidak normal distribusi data dalam suatu model uji.

Uji multikolinearitas bertujuan untuk menguji apakah pada model regresi ditemukan adanya korelasi antar variable bebas. Cara mendeteksi ada atau tidaknya korelasi antar sesama variabel bebas dapat dilihat dari nilai tolerance dan nilai variance inflation factor (VIF). Jika nilai tolerance lebih dari 10 persen $(0,1)$ VIF kurang dari 10, maka dikatakan tidak ada multikolinearitas. Hasil uji multikolinearitas antar variable bebas penelitian ini dapat dilihat pada tabel 6 sebagai berikut:

Tabel 6.

Hasil Uji Multikolinearitas

\begin{tabular}{lccl}
\hline \multicolumn{1}{c}{ Variabel } & Tolerance & VIF & Keterangan \\
\hline Pengembangan Karir $\left(\mathrm{X}_{1}\right)$ & 0,329 & 3,039 & Bebas Multikolinearitas \\
Kompensasi $\left(\mathrm{X}_{2}\right)$ & 0,373 & 2,682 & Bebas Multikolinearitas \\
Komitmen Organisasional $\left(\mathrm{X}_{3}\right)$ & 0,617 & 1,620 & Bebas Multikolinearitas \\
\hline
\end{tabular}

Sumber:Data diolah, 2018

Pada Tabel 6 menunjukkan bahwa masing-masing variable bebas memiliki nilai tolerance diatas 0,1 dan nilai variance factor (VIF) kurang dari 10, sehingga dapat dinyatakan bahwa tidak ada multikolinearitas antar variabel bebas. hal ini berarti tidak ada kolerasi atau keterikatan antar variabel bebas yang diteliti.

Uji heterokedostisitas bertujuan untuk mengetahui apakah dalam model regresi terjadi ketidaksamaan varians dari residual satu pengamatan ke pengamatan lain yang dilakukan dengan uji Glejser. Jika tidak ada satu pun variable bebas yang berpengaruh signifikan terhadap nilai absolute residual atau 
nilai signifikansinya di atas 0,05 maka tidak mengandung gejala heteroskedastisitas. Hasil uji heteroskedastisitas variable bebas penelitian ini dapat dilihat pada Tabel 7 .

Tabel 7.

Hasil Uji Heteroskedastisitas

\begin{tabular}{clcccccc}
\hline Model & & \multicolumn{2}{c}{$\begin{array}{c}\text { Unstandardized } \\
\text { Coefficients }\end{array}$} & $\begin{array}{c}\text { Standardized } \\
\text { Coefficients }\end{array}$ & t & Sig. \\
& & B & Std. Error & Beta & & \\
\hline 1 & (Constant) & 1.740 & .704 & & 2.472 & .015 \\
2 & Pengembangan Karir & -.107 & .055 & -.353 & -1.950 & .054 \\
3 & Kompensasi & .079 & .050 & .269 & 1.582 & .117 \\
4 & Komitmen & -.003 & .031 & -.012 & -.093 & .926 \\
\hline & Organisasional & & & & &
\end{tabular}

Berdasarkan tabel 7 diatas dapat dilihat bahwa hampir semua variabel memiliki nilai sig > 0,05 ini berarti pada model regresi tidak terjadi gejala heteroskedasitisitas

Tabel 8.

Rangkuman Hasil Analisis Regresi Linear Berganda

\begin{tabular}{|c|c|c|c|c|c|}
\hline \multirow[t]{2}{*}{ Model } & \multicolumn{2}{|c|}{$\begin{array}{c}\text { Unstandardized } \\
\text { Coefficients }\end{array}$} & \multirow{2}{*}{$\begin{array}{c}\text { Standardized } \\
\text { Coefficients } \\
\text { Beta }\end{array}$} & \multirow[t]{2}{*}{$\mathbf{T}$} & \multirow[t]{2}{*}{ Sig. } \\
\hline & B & Std. Error & & & \\
\hline 1 (Constant) & $-0,173$ & 1,203 & - & $-0,144$ & 0,086 \\
\hline Pengembangan Karir & 0,339 & 0,094 & 0,332 & 3,601 & 0,001 \\
\hline Kompensasi & 0,371 & 0,085 & 0,378 & 4,358 & 0,000 \\
\hline Komitmen Organisasi & 0,217 & 0,053 & 0,277 & 4,112 & 0,000 \\
\hline $\mathrm{R}$ & & & & & 0,868 \\
\hline R Square & & & & & 0,753 \\
\hline F Statistik & & & & & 89,643 \\
\hline Sig. F & & & & & 0,000 \\
\hline
\end{tabular}

Berdasarkan persamaan hasil regresi linear berganda melalui uji SPSS, dapat dijelaskan bahwa nilai koefisien regresi pengembangan karir $\left(\mathrm{X}_{1}\right)$ sebesar 0,339 memiliki arti pengembangan karir berpengaruh positif terhadap retensi karyawan 
di Bintang Kuta Hotel, apabila nilai pengembangan karir $\left(\mathrm{X}_{1}\right)$ naik maka nilai retensi (Y) akan mengalami peningkatan.

Nilai koefisien regresi kompensasi $\left(\mathrm{X}_{2}\right)$ sebesar 0,371 memiliki arti bahwa kompensasi berpengaruh positif terhadap retensi karyawan di Bintang Kuta Hotel, bila nilai kompensasi $\left(\mathrm{X}_{2}\right)$ naik maka nilai dari retensi $(\mathrm{Y})$ akan mengalami peningkatan.

Nilai koefisien regresi komitmen organisasional $\left(\mathrm{X}_{3}\right)$ sebesar 0,217 memiliki arti komitmen organisasional memiliki pengaruh positif terhadap retensi karyawan di Kuta Bintang Hotel, apabila nilai komitmen organisasional $\left(\mathrm{X}_{3}\right)$ naik maka nilai dari retensi (Y) akan mengalami peningkatan.

Analisis Koefisien Determinasi digunakan untuk mengukur seberapa jauh kemampuan semua variabel bebas dalam menerangkan variasi dari variabel dependennya (Ghozali, 2016:95). Dalam penelitian ini koefisien determinasi dilihat melalui nilai $\mathrm{R}^{2}$. Adapun nilai dari $\mathrm{R}^{2}$ pada penelitian ini telah disajikan pada Tabel 4.9dapat dilihat bahwa nilai dari $\mathrm{R}^{2}$ sebesar 0,753 dimana memiliki arti bahwa 75,3\% variabel retensi dapat dijelaskan oleh variabel pengembangan karir, kompensasi dan komitmen organisasional. Sedangkan sisanya sebesar 24,7 $\%$ dipengaruhi oleh variabel lain diluar daripenelitian ini.

Hipotesis satu $\left(\mathrm{H}_{1}\right)$ dalam penelitian ini menyatakan bahwa pengembangan karir berpengaruh positif dan signifikan terhadap retensi karyawan. Sehingga dapat disimpulkan bahwa hasil ini menerima $\mathrm{H}_{1}$ yakni pengembangan karirberpengaruh positif dan signifikan terhadapretensi. Hasil penelitian ini sesuai dengan penelitian yang dilakukan oleh Pratiwi and Sriathi (2017), Sitati et 
al.(2016), Kuncoro (2013), Prince (2005), Agolla (2009), Cho et al. (2009) dan Kwenin (2013)yang menyatakan bahwa pengembangan karir berpengaruh positif dan signifikan terhadap retensi karyawan. Sutherland (2004) menyatakan bahwa organisasi yang memberikan pengembangan karir kepada karyawan, secara tidak langsung berhubungan dengan pekerjaan mereka maka karyawan cenderung mempertahankan pekerjaan mereka untuk dapat memperoleh pengetahuan yang lebih luas. Cardy and Lengnick-Hall (2011), Kroon and Freese (2013), menemukan bahwa peluang pengembangan karir dapat secara positif meningkatkan komitmen karyawan untuk tinggal di organisasi.

Hipotesis dua $\left(\mathrm{H}_{2}\right)$ dalam penelitian ini menyatakan bahwa kompensasi berpengaruh positif dan signifikan terhadap retensi karyawan. Sehingga dapat disimpulkan bahwa hasil ini menerima $\mathrm{H}_{2}$ yakni kompensasiberpengaruh positif dan signifikan terhadapretensi. Hasil penelitian ini sesuai dengan penelitian yang dilakukan oleh Putra and Agoes (2016), Sarmand et al. (2016), Hafantiet al.(2015),Anis et al. (2011), Kumar et al. (2012), Milkovich and Newman (2004), Panggabean (2014), Michael et al. (2016) menyatakan bahwa kompensasi memiliki pengaruh positif dan signifikan terhadap retensi karyawan. Begitu juga dengan penelitian Sumarto (2009) menunjukan bahwa semakin menarik faktor kompensasi akan semakin mengurangi niat karyawan untuk meninggalkan organisasi sehingga retensi tetap terjaga. Sebaliknya semakin rendah tingkat kompensasi yang diterima semakin mendorong karyawan untuk meninggalkan organisasi dan mencari alternatif pekerjaan di tempat sehingga retensi menjadi menurun. 
Hipotesis tiga $\left(\mathrm{H}_{3}\right)$ dalam penelitian ini menyatakan bahwa komitmen oganisasional berpengaruh positif dan signifikan terhadap retensi karyawan. Sehingga dapat disimpulkan bahwa hasil ini menerima $\mathrm{H}_{1}$ yakni pengembangan karirberpengaruh positif dan signifikan terhadapretensi. Hasil penelitian ini sesuai dengan penelitian yang dilakukan oleh Fukuoka (2014), Aniset al.(2011), Rose, S. and Raja, K.G. (2016), Coetzee and Botha (2012), Tung et al. (2014), Coetzee and Botha (2012), Naqri, S. and Bashir, S. (2015), Mowday et al. (1982:219) menyatakan bahwa komitmen organisasi secara positif mempengaruhi retensi karyawan. Naqvi, S. and Bashir, S. (2015) menyatakan bahwa terdorongnya komitmen organisasional pada karyawan akan meningkatkan retensi karyawan. Mehta et al. (2014) menyatakanagar organisasi dapat bertahan dalam persaingan yang semakin hari semakin meningkat, sangat penting untuk mempertahankan karyawan terbaik mereka yaitu dengan menjaga komitmen mereka terhadap organisasi.

\section{SIMPULAN DAN SARAN}

Berdasarkan hasil dan pembahasan yang telah diuraikan pada bab sebelumnya, maka diperoleh simpulan bahwa pengembangan berpengaruh positif dan signifikan terhadap retensi karyawan pada Bintang Kuta Hotel. Hal ini menunjukkan bahwa semakin baik pengembangan karir yang diberikan terhadap karyawan maka semakin tinggi retensi karyawan dalam perusahaan.

Kompensasi berpengaruh positif dan signifikan terhadap retensi karyawan pada Bintang Kuta Hotel. Hal ini menunjukkan bahwa semakin baik kompensasi 
yang diberikan terhadap karyawan maka semakin tinggi retensi karyawan dalam perusahaan.

Komitmen organisasional berpengaruh positif dan signifikan terhadap retensi karyawan pada Bintang Kuta Hotel. Hal ini menunjukkan bahwa semakin kuat Komitmen Organisasional karyawan maka semakin tinggi retensi karyawan dalam perusahaan.

Saran yang dapat diberikan dari penelitian adalah saran secara teoritis yang dapat diberikan dari penelitian ini adalah perusahaan harus memperhatikan pegembangan karir, kompensasi, dan komitmen organisasional dalam perusahaan untuk meningkatkan retensi karyawan. Variabel kompensasi menjadi salah satu variabel yang sangat penting diperhatikan karena memiliki nilai standar koefisien paling tinggi.

Perusahaan diharapkan adil dalam memberikan kesempatan pada karyawan untuk naik jabatan dan menyediakan informasi mengenai syarat-syarat yang lengkap untuk menempati suatu jabatan baru. Perusahaan juga diharapkan merubah pola pikir pegawai dengan menciptakan lingkungan kerja yang kondusif sehingga tercipta suasana bekerja yang positif.

Perusahaan sebaiknya meninjau kembali jumlah gaji yang diperoleh para karyawan agar sesuai dengan tingkat jabatan dan beban kerja masing-masing karyawan. Perusahaan juga diharapkan untuk mempertimbangkan besaran insentif dengan prestasi kerja yang telah dicapai karyawan.

Perusahaan sebaiknya lebih menjaga komitmen karyawan dengan cara memperhatikan karyawan dan menjaga hubungan yang baik dengan karyawan. 
Perusahaan dirasa perlu meninjau kembali apa saja yang sudah perusahaan berikan kepada karyawan.

Perusahaan sebaiknya memberikan kesempatan pelatihan dan kontinuitas pelatihan yang adil kepada setiap karyawan. Diharapkan perusahaan juga mengapresiasi setiap pekerjaan yang sudah berhasil dilakukan oleh karyawan.

Saran bagi penelitian selanjutnya yaitu menggunakan variabel lain seperti iklim organisasi dan stres kerja. Penelitian selanjutnya diharapkan untuk mengambil sampel di luar lingkungan industri perhotelan seperti perbankan, rumah sakit, ataupun sekolah dan diharapkan menggunakan teknik analisis yang berbeda seperti analisis jalur.

\section{REFERENSI}

Anis. (2011). Employee Retention Relationship to Training and Development: A Compensation Perspective. African Journal of Business Management. 5(7): 2679-2685.

Anis, Atif.,Kashif-ur-Rehman1., Ijaz-Ur-Rehman, Muhammad Asif Khan and Asad Afzal Humayoun. (2011). Impact of Organizational Commitment on Job Satisfaction and Employee Retention in Pharmaceutical Industry. African Journal of Business Management. 5(17): 7316-7324.

Cao, Zhoutgo., Jinxi Chen and Yixiao Song. (2013). Does Total Reward Reduce The Core Employees Turnover Intention. International Journal of Business and Management. 8(20): 62-75.

Cardy, R.L., and Lengnick-Hall.(2011). Will They Stay or Will They Go? Exploring a Customer-Oriented Approach to Employee Retention. Journal of Business and Psychology. 26 (2): 213-217.

Cho, S., Johanson and Guchait, P. (2009). Employee Intent To Leave: A Comparison Of Determinants Of Intent To Leave Versus Intent To Stay. International Journal of Hospitality Management. 28(3): 374-381.

Coetzee, M., and Botha, J. (2012). The Languishment of Employee Commitment in The Light of Perceptions of Fair Treatment in The Workplace. SA 
Journal of Human ResourceManagement/SA Tydskrif vir Menslikehulpbronbestuur. 10(2):1-11

Dessler, Gery. (2013). Human Resources Management: Edition 13. Pearson. England

Dockel, A., Basson, J.S., and Coetzee. (2006). The Effect of Retention Factors on Organizational Commitment:An Investigation of High Technology Employee. Journal Human Resource Management. 46(1): 47-55.

Fukuoka, Sonia. (2014). Factors That Predict Employee Retention in Profit and Non-Profit Organizations. Global Journal of Human Resource Management. 2(4):1-8

Ghozali, I. (2012). Aplikasi Analisis Multivariate dengan Program SPSS. Badan Penerbit Universitas Diponegoro. Semarang

Hafanti, Oktina., Rahman Lubis dan Hafasnudi. (2015). Pengaruh Kompensasi, lingkungan kerja dan Desain Tugas Terhadap Kepuasan Kerja dan Dampaknya Terhadap Retensi Karyawan Palang Merah Indonesia (PMI) Provinsi Aceh. Jurnal Manajemen Pasca Universitas Syiah Kuala. 4(1):164-173.

Hasibuan, Malayu S. P.(2011). Manajemen Sumber Daya Manusia. Edisi revisi. PT. Bumi Aksara: Jakarta.

Jennifer A, Carsen. (2005). HR How To Employee Retention. Chicago : J.D. CCH Incorporated.

Karthi, R. and P. J Devi. (2012). A Study On Employee Retention In Leading Multional Automobile Sector In India. International Journal of Management Research and Reviews.2(9): 1474-1482.

Kroon, B. and Freese, C. (2013). Can HR Practices Retain Flexworkers with Their Agency? International Journal of Manpower. 34(8): 899-917.

Kumar, Rames., Charles Ramendran dan Peter Jacob. (2012). A Study on Turnover Intention in Fast Food Industry: Employees Fit to the Organizational. Journal of Academic Research in Business and Social Sciences. 2 (5): 9-42.

Kwenin, Daisy Ofosuhene. (2013). Relationship Between Work Environment, Carrer Development Opportunities and Employee Retention in Vodafone Ghana Limited. Global Jurnal of Human Resoirces Management. 1(4): 1 -9 . 
Lubis, Rahman. (2015). Pengaruh Kompensasi, Lingkungan Kerja Dan Desain Tugas Terhadap Kepuasan Kerja Dan Dampaknya Terhadap Retensi Karyawan PMI. Jurnal Manajemen. 4(1): 164-173.

Luthans, Fred. (2005). Organizational Behavior: Tenth Edition. New York USA: McGraw-Hill.

Mathis Robert L dan Jackson John H. (2006). Human Resource Management, alih bahasa. Salemba Empat. Jakarta.

Mehta, Mita., and Aarti Kurbetti. (2014). Study on Employee Retention and Commitment. International Journal of Advance Research in Computer Science and Management Studies. 2(2): 154-164.

Meyer, J.P., and Allen, N.J. (1991). A Three - Component Conzeptualization of Organiational Commitment. Human Resource Management Review. 1(1): $61-89$

Meyer, J.P., C.A. Smith. (2000). HRM Practices and Organizational Commitment: Test of AMediation Model. Canadian Journal of Administrative Sciences. 17 (4): 319-331.

Michael, Babu., Prince, Andrew., and Chacko Anney. (2016). Impact of Compensation Packages and Employee Retention. CLEAR International Journal of Research in Commerce and Management. 7(10): 36-40.

Milkovich, G.M. and Newman, J.M. (2004).Compensation. 8th Edition, Irwin McGraw-Hill, Burr Ridge.

Miner, J.B. (1992). Industrial and Organizational Psychology. New York: Academic Press.

Mowday, R.T., Porter, L.W., and Steers, R.M. (1982). Employee Organizational Linkages: The Psychology of Commitment, Absenteeism, and Turnover. In P. Warr (Ed.). Academic Press.

Mudayen. (2010). Pengaruh Kompensasi, Pengembangan Karir, Lingkungan Dan Pengalaman Terhadap Motivasi Dan Prestasi Kerja. Jurnal Penelitian. 13(2): 169-198.

Mustika, I. K. (2012). Analisis Budaya Organisasi dan Kepuasan Kerja Melalui Komitmen Pengaruhnya Terhadap Intent to Leave Karyawan pada Industri Jasa Perhotelan di Kabupaten Badung dan Kota Denpasar. Jurnal Mitra Ekonomi dan Manajemen Bisnis. 3(1): 1-24. 
Naqvi, S. M. M. R., and Bashir, S. (2015). IT-Expert Retention Through Organizational Commitment: A Study of Public Sector Information Technology Professionals in Pakistan. Journal of Social Sciences. 4(5): 60-75.

Tung N. Nguyen, Khuong N. Mai, and Phuong V. Nguyen. (2014). Factors Affecting Employees Organizational Commitment-A Study of Banking Staff in Ho Chi Minh City, Vietnam. Journal of Advanced Management Science. 2(1): 7-11.

Ongori, H.\& Agolla, J.E. (2009). Paradigm Shift in Managing Career Plateau in Organization: The Best Strategy to Minimize Employee Intention to Quit. African Journal of Business Management. 3(6): 268-271.

Panggabean, Mutiara Sibarani. (2014). Pengaruh Kompensasi Terhadap Retensi Karyawan Melalui Kepuasan Kerja dan Komitmen Afektif Pada Beberapa Rumah Sakit di DKI Jakarta. Jurnal Manajemen Pascasarjana Universitas Syiah Kuala. 7(1): 199-217.

Pratiwi, Ni Luh Yunia dan Anak Agung Ayu Sriathi. (2017). Pengaruh Lingkungan Kerja dan Pengembangan Karir Terhadap Retensi Karyawan Pada Hotel Santika Nusa Dua Bali. E-Jurnal Manajemen Udayana. 6(3): 1478-1506.

Prince, B.J. (2005). Career-Focused Employee Transfer Processes. Career Development International Journal. 10(4):293-309

Putra, Ida Bagus Gede Swambawa dan Agoes Ganesha Rahyuda. (2016). Pengaruh Kompensasi, Lingkungan Kerja, dan Perceived Organizational Support (POS) Terhadap Retensi Karyawan Green Villas Hotel Tuban Bali.E-Jurnal Manajemen Udayana. 5(2): 810 - 837.

Ragupathi. (2013). The Employee Retention Practices of MNC'S in Hyderabad. Research Journal of Management Sciences.2(4): 21-24.

Robbins, Stephen P. \& Timothy A. Judge. (2015). Perilaku Organisasi. 16 ed. Jakarta. Salemba Empat.

Rose, Swapna and Raja, K. G. (2016). Role of HR Practices, Job Satisfaction, and Organization Commitment in Employee Retention. CLEAR International Journal of Research in Commerce and Management. 7(10): 1-3.

Sari, Eliana., Joni Sinulingga. (2011). Pengaruh Pengembangan Karir Dan Kompensasi Terhadap Motivasi Karyawan. Jurnal Ilmiah Penelitian Manajemen Manajerial. 2(1): 431-440. 
Sarmand, M., M. Muneeb., M. Shamim., M. Saleh., Almas Malik. (2016). Motivation and Compensation as Predictors of Employees' Retention: Evidence From Public Sector Oil and Gas Selling Organizations. Journal of Behavioural Sciences. 26(2): 174-187.

Setiawan, R., dan Brian, H. (2013). Pengaruh Komitmen Organisasional Terhadap Kepuasan Kerja Karyawan Paparon's Pizza City Of Tomorrow.Jurnal Studi Manajemen dan Organisasi. 1(1):21-41.

Siagian, Sondang P. (2011). Manajemen Sumber Daya Manusia. Jakarta: Bumi Aksara.

Simamora. (2004). Manajemen Sumber Daya Manusia. Edisi Ketiga. Yogyakatra: STIE YKPN.

Sitati, Norah., Susan Were., \& Gichuci. A. (2016). Effects Of Career Development on Employee Retention in Hotel Industry in Kenya. The Strategic Journal of Business and Change Management. 3(50): 940-955.

Sofyandi, Herman. (2008). Manajemen SumberDaya Manusia.

Yogyakarta:Grahailmu.

Sugiyono.(2016). Metode Penelitian Bisnis. Jakarta: PT. Gramedia Pustaka.

Sumarto. (2009). Meningkatkan Kompensasi, Kepuasan Kerja dan Motivasi untuk Mengurangi Labour Turnover Intention. Jurnal Riset Ekonomi dan Bisnis. 9(1): 40-51.

Sutherland. (2004). Factors Affecting the Retention of Knowledge Workers.Journal of Human Resource Management. 2(2): 55-64.

Umar, Husein. (2010). DesainPenelitian MSDM dan Perilaku Karyawan Paradigma Posotivistik dan Berbasis Pemecahan Masalah. Jakarta: PT. Raja GrafindoPersada.

Utama, Made Suyana. (2012). Aplikasi Analisis Kuantitatif. Edisi Keenam. Denpasar: Fakultas Ekonomi dan Bisnis Universitas Udayana.

Woodruff, D. (1999). Understanding Motives. Journal : Executive Excellence (EEX). 16(4): 1-7. 